\title{
Prevalence of ATM sequence variants in Northern plains American Indian cancer patients
}

\author{
Daniel G. Petereit ${ }^{1,2}$ *, L. Jennifer Hahn ${ }^{2}$, Shalini Kanekar ${ }^{1}$, Amy Boylan ${ }^{1}$, Søren M. Bentzen ${ }^{2}$, Mark Ritter $^{2}$ \\ and Amy R. Moser ${ }^{2}$
}

${ }^{1}$ Rapid City Regional Hospital, John T. Vucurevich Cancer Care Institute, Rapid City, SD, USA

${ }^{2}$ Department of Human Oncology, University of Wisconsin School of Medicine and Public Health, Madison, WI, USA

\section{Edited by:}

Jann Sarkaria, Mayo Clinic, USA

Reviewed by:

Shisuo Du, New York University, USA Gaspar Kitange, Mayo Clinic, USA

\section{${ }^{*}$ Correspondence:}

Daniel G. Petereit, Rapid City

Regional Hospital, John T. Vucurevich Cancer Care Institute, 353 Fairmont

Boulevard, Rapid City, SD 57702, USA e-mail:dpetereit@regionalhealth.com

\begin{abstract}
Purpose: To identify sequence variants of the ataxia telangiectasia mutated (ATM) gene and establish their prevalence rate among American Indian (Al) as compared with non-Al cancer patients.
\end{abstract}

Materials and Methods: DNA was isolated from blood samples collected from $100 \mathrm{Al}$ and 100 non-Al cancer patients undergoing radiation therapy, and a blinded assessment of the ATM sequence was conducted. Quantitative PCR assessment of copy number for each exon was also performed. The main outcome measure was the prevalence of ATM variants in the two patient populations.

Results: No statistically significant differences for total prevalence of ATM variants among $\mathrm{Al}$ and non-Al patients were found. Of the 25 variants identified, 5 variants had a prevalence of $>2 \%$, of which 4 occurred at a rate of $>5 \%$ in one or both groups. The prevalence of these four variants could meaningfully be compared between the two groups. The only statistically significant difference among the groups was the c. $4138 \mathrm{C}>\mathrm{T}$ variant which is predicted not to affect protein function, seen in $8 \%$ of Al versus $0 \%$ of non-Al patients $(P=0.007)$. No exonic copy number changes were found in these patients.

Conclusion: This study is the first to determine the prevalence of ATM variants in Als.

\section{INTRODUCTION}

Radiation has a pivotal role in the management of human cancer with approximately $50 \%$ of all cancer patients receiving it at some point during their course of treatment. While radiation therapy is often successful in the local eradication of tumor cells, late normal tissue effects may significantly reduce organ function and health-related quality of life in a proportion of long term cancer survivors (1). Individual variability in normal tissue response to fractionated radiotherapy has been observed in both clinical and laboratory studies. The risk of radiation induced toxicities is affected by treatment related factors such as total radiation dose, dose per fraction, volume of normal tissue irradiated, and other patient related factors $(2,3)$. These factors alone are not sufficient to account for the variability seen among patients, however. Hence, identifying new genetic biomarkers having potential relevance to toxicities and incorporating these into traditionally used assessment tools will help personalize treatment plans and potentially increase efficacy and reduce toxicities.

The induction and processing of radiation damage to normal cells and tissues involve multiple molecular pathways from DNA damage repair to wound healing responses and tissue remodeling (4). Genetic variability in genes that regulate these processes can either play a protective role or render an individual susceptible to radiation induced cell damage. Ataxia telangiectasia mutated (ATM) is a serine threonine kinase that phosphorylates several substrates involved in diverse functions such as repair of double stranded breaks in DNA, cell cycle regulation, radiosensitivity, and oxidative stress. A-T is an autosomal recessive disorder and is a result of deleterious mutation in the ATM gene (5). Typical manifestations are neurological deterioration and ocular telangiectasia and increased susceptibility to radiation toxicities (6).

Skin fibroblasts from A-T patients show a threefold increase in radiosensitivity when irradiated in vitro compared to normal human fibroblasts (7). Although A-T homozygotes are rare, A-T heterozygosity is estimated to occur in about $1-2 \%$ of the Caucasian population in the US (8). Heterozygosity for mutations shown to result in AT may confer a greater risk of developing cancer and increased radiosensitivity to carriers (9).

American Indians (AIs) appear more sensitive to fractionated radiotherapy as reported by our group. This was evident by AIs developing higher rates of G3 skin and mucosal reactions as compared to non-AI patients (10). The ATM gene has not been studied in Northern Plains AIs, a population that exhibits disproportionate burden of cancer mortality. We hypothesized that a significant proportion of $\mathrm{AI}$ that manifest toxicities in response to radiation therapy carried deleterious variants in the ATM gene. In this study we aimed to determine the prevalence of ATM variants among AI cancer patients and compare this to non-AI cancer patients. The ATM study is one of many conducted by our group known as Walking Forward which has been in existence since 2002. This NCI 
funded program addresses cancer disparities through patient navigation, enrollment to clinical trials, and determinants of cancer screening and delays to cancer diagnosis and treatment (11).

\section{MATERIALS AND METHODS \\ PATIENTS}

Peripheral blood was obtained from 202 patients (101 AIs and 101 non-AIs) seen during a routine treatment visit or follow-up. Patients were staged according to American Joint Committee on Cancer standards. $10.5 \%$ of patients were treated with palliative intent and $89.5 \%$ with curative intent. The study was approved by the Rapid City Regional Hospital's Institutional Review Board and by all Tribal entities that were a part of this study. All patients who participated were consented.

\section{DNA EXTRACTION AND SEOUENCING}

Genomic DNA was extracted from peripheral blood lymphocytes via the PAXgene Blood DNA Kit (Qiagen) and dissolved into $600 \mu \mathrm{l}$ volumes of Buffer BG4 (Qiagen). The concentration of the dissolved gDNA was determined using a SpectraMax 190 Microplate Reader (Molecular Devices) or Nanodrop 1000 spectrophotometer (Thermo Scientific).

\section{ATM EXON CHARACTERIZATION}

Coding exons 4 through 65 and flanking intronic regions were amplified individually, except for exons 4 and 5, 23 and 24, and 43 and 44 which were amplified as single products. Exon numbering is based on transcript NM_000051.3 as described elsewhere (12). We used a set of primers as previously published (13) with a few alterations. Amplification was done with the MasterTaq kit $\left(5^{\prime}\right)$ in $20 \mu \mathrm{l}$ volumes consisting of $1 \times$ TaqMaster solution, $1.5 \mathrm{mM} \mathrm{Mg}{ }^{2+}, 0.2 \mathrm{mM}$ mixed dNTP's, $0.5 \mathrm{U} / \mu \mathrm{ltaq}, 8 \mathrm{pmols}$ of sense primer, 8 pmols of anti-sense primer, and $\sim 125 \mathrm{ng}$ gDNA in reagent grade water. Sequencing was done with the Big Dye v3.1 solution in $10 \mu \mathrm{l}$ volumes using $4 \mathrm{pmol}$ of one primer, $0.25 \mu \mathrm{l}$ Big Dye v3.1, $3.75 \mu l 2.5 \times$ buffer (19 mM Tris-HCl, $180 \mathrm{mM}$ Tris, $\left.5 \mathrm{mM} \mathrm{MgCl}_{2}, \mathrm{pH} 9.0 \pm 0.5\right), \sim 1$ ng DNA per 100bp of amplicon length and reagent grade water.

Multiplex PCR was done to test the copy number of each exon. An unrelated non-polymorphic marker on chromosome 7 was included in each mix to serve as a non-ATM control peak. About $\sim 125$ ng gDNA was amplified with $5 \mu 12 \times$ Master Mix from the Multiplex PCR kit (Qiagen), $2 \mu \mathrm{l}$ of a $0.5: 50 \mu \mathrm{M}$ mix of sense to anti-sense primers, and $1 \mu \mathrm{l}$ each of $7 \mu \mathrm{M}$ FAM- or HEX-labeled additional universal sense primers. The sense primers for each exon were designed to bind one of the universal sense primers. Amplification products were diluted 1:5 with water. GeneFlo 625 DNA Markers (ChimerX) were diluted $0.3 \mu \mathrm{l}$ in $15 \mu \mathrm{l}$ distilled water per sample. Then $1 \mu \mathrm{l}$ of diluted amplicons was mixed with $15.3 \mu \mathrm{l}$ diluted markers, denatured at $95^{\circ} \mathrm{C}$, and immediately cooled. The products were analyzed with an ABI 3730xl DNA analyzer.

\section{VARIATION DISCOVERY AND CHARACTERIZATION}

Traces were checked for quality, processed into a multi-alignment assembly for each exon, and scanned for variations using visual inspection, SequenceScanner v1.0 (Applied Biosystems), and the
Staden Package 1.6.0 for Mac and 2002 for Windows (14). Potential variants were confirmed based on sequencing in the opposite direction and/or a second or third sequencing run. Variants were named according to the recommendations of the Human Genome Variation Society. PolyPhen-2 (15), a software tool that predicts the likely impact of an amino acid substitution on the function of a human protein, was run on each variant.

Fragment files from the exon copy number tests were downloaded and analyzed without additional manipulation in Peak Scanner v1.0 (Applied Biosystems).

\section{STATISTICS}

Fisher's Exact Test was used to test for an association between ethnicity and prevalence of a specific genotype. Analyses were performed using IBM SPSS version 20.0.0. Statistical significant associations were defined as those where the two-sided $P$-value was lower than or equal to 0.05 . Prevalence estimates are specified in percent together with their exact 95\% confidence limits.

\section{OBTAINING CONSENT}

While there were initial concerns that this study could not be opened, or accrued to, due to concerns of genetic testing in a disparate population, IRB approval was rapidly obtained with only a few patients refusing participation. Patients were eager to enroll as they believed it could help the next generation of cancer patients.

\section{RESULTS}

A total of 25 variants were identified in this patient population; 6 would be predicted to be silent, and 19 would be predicted to result in change in the protein sequence (Table 1). None would be predicted to truncate the protein. Of those missense variants, 14 were predicted to be possibly or probably damaging to protein function. None of the variants identified in this study have been associated with the development of A-T. One of the variants (7228 $\mathrm{T}>\mathrm{C}$ ) found in one non-AI patient, was not previously registered in the NCBI dSNP database. No statistically significant difference for total prevalence of variants was found among AI (40\%) and non-AI $(48 \%)$ patients $(P=0.32)$. Nineteen of the variants were found in the non-AI patients and 12 in the AI patients. Five variants had a prevalence of $\geq 2 \%$, of which four occurred at a rate of $>5 \%$ in one or both groups (Table 2). The prevalence of these could meaningfully be compared statistically in the two groups. The only statistically significant difference among the groups was the c. $4138 \mathrm{C}>\mathrm{T}$ variant seen in $8 \%$ of AI versus $0 \%$ of non-AI patients $(P=0.007)$. However, the PolyPhen-2 software tool predicts that this variant (His1380Tyr) will not affect protein function. Also another variant, variant c. $5557 \mathrm{G}>\mathrm{A}$, had a prevalence of $25 \%$ in non-AI versus $14 \%$ in AI patients $(P=0.07)$ but is predicted not to affect protein function. Three patients are homozygous for this variant, all in the non-AI group. There was one additional non-AI patient who is homozygous for the $\mathrm{c} .378 \mathrm{C}>\mathrm{T}$ variant which is also predicted to be benign. The prevalence of those variants predicted to result in potentially deleterious missense mutations was $7 \%$ among non-AI and $7 \%$ among $\mathrm{AI}$ patients.

Sixteen patients had more than one variant, in four cases this involved the c.4578C $>\mathrm{T}$ and $\mathrm{c} .5557 \mathrm{G}>\mathrm{A}$ pair of variants (Table 3). Two patients had three variants. We were unable to 
Table 1 | List of exonic variants

\begin{tabular}{|c|c|c|c|c|c|c|c|}
\hline $\begin{array}{l}\text { cDNA-level } \\
\text { variation name } \\
\text { (based on }\end{array}$ & rs No. & Exon & $\begin{array}{l}\text { Theoretical } \\
\text { protein-level } \\
\text { variation name }\end{array}$ & $\begin{array}{l}\text { PolyPhen-2 }{ }^{\mathrm{a}} \text { results } \\
\text { (humdiv-trained) }\end{array}$ & $\begin{array}{l}n \text { Total } \\
\text { patients }\end{array}$ & $\begin{array}{l}n \text { Caucasian } \\
\text { patients }\end{array}$ & $\begin{array}{l}n \text { Native } \\
\text { American } \\
\text { patients }\end{array}$ \\
\hline LRG_135) & & & & & & & \\
\hline
\end{tabular}

\begin{tabular}{|c|c|c|c|}
\hline \multicolumn{4}{|l|}{ Non-synonymous variants } \\
\hline c. $[94 \mathrm{C}>\mathrm{T}] ;[=]$ & rs148061139 & 05 & p. $[(\operatorname{Arg} 32$ Cys $)] ;[(=)]$ \\
\hline c. $[146 \mathrm{C}>\mathrm{G}] ;[=]$ & rs1800054 & 05 & p. [(Ser49Cys)];[(=)] \\
\hline c. $[202 A>G] ;[=]$ & rs35389822 & 06 & p.[(lle68Val)];[(=)] \\
\hline c. [378T>A];[378T>A] & rs2234997 & 07 & p.[(Asp126Glu)];[(Asp126Glu)] \\
\hline c. $[998 \mathrm{C}>\mathrm{T}] ;[=]$ & rs28904919 & 10 & p. [(Ser333Phe)];;(=)] \\
\hline c. $[1229 \mathrm{~T}>\mathrm{C}] ;[=]$ & rs56128736 & 11 & p. [(Val410Ala) $] ;[(=)]$ \\
\hline c. $[1744 \mathrm{~T}>\mathrm{C}] ;[=]$ & rs2235006 & 13 & p. $[($ Phe582Leu) $] ;[(=)]$ \\
\hline c. $[1960 \mathrm{C}>\mathrm{A}] ;[=]^{\mathrm{b}}$ & - & 15 & p. $[(G \ln 654 L y s)] ;[(=)]$ \\
\hline c. $[2119 T>C] ;[=]$ & rs4986761 & 15 & p. [(Ser707Pro)];[(=)] \\
\hline c. $[2149 \mathrm{C}>\mathrm{T}] ;[=]$ & rs147515380 & 16 & p. $[(\operatorname{Arg} 717 \operatorname{Trp})] ;[(=)]$ \\
\hline c. $[2572 \mathrm{~T}>\mathrm{C}] ;[=]$ & rs1800056 & 19 & p. $[($ Phe858Leu)];;(=)] \\
\hline c. $[3161 \mathrm{C}>\mathrm{G}] ;[=]$ & rs1800057 & 24 & p. $[($ Pro1054Arg) $] ;[(=)]$ \\
\hline c. $[3383 A>G] ;[=]$ & rs56398245 & 25 & p. $[(G \ln 1128 \operatorname{Arg})] ;[(=)]$ \\
\hline c. $[4138 \mathrm{C}>\mathrm{T}] ;[=]$ & rs3092856 & 30 & p. [(His1380Tyr)];[(=)] \\
\hline c. $[4258 \mathrm{C}>\mathrm{T}] ;[=]$ & rs1800058 & 31 & p.[(Leu1420Phe)];;(=)] \\
\hline c. $[5071 \mathrm{~A}>\mathrm{C}] ;[=]$ & rs1800059 & 36 & p. [(Ser1691Arg)];[(=)] \\
\hline c. $[5557 \mathrm{G}>\mathrm{A}] ;[=]$ & rs1801516 & 39 & p. [(Asp1853Asn)];[(=)] \\
\hline c. $[5557 \mathrm{G}>\mathrm{A}] ;[5557 \mathrm{G}>\mathrm{A}]$ & rs1801516 & 39 & p.[(Asp1853Asn)];;(Asp1853Asn)] \\
\hline c. $[5558 \mathrm{~A}>\mathrm{T}] ;[=]^{\mathrm{C}}$ & rs1801673 & 39 & p.[(Asp1853Val)];[(=)] \\
\hline c. $[7228 \mathrm{~T}>\mathrm{C}] ;[=]^{\mathrm{d}}$ & rs193302874 & 51 & p. $[($ Phe2410Leu $)] ;[(=)]$ \\
\hline
\end{tabular}

Non-synonymous variants

c. $[94 \mathrm{C}>\mathrm{T}] ;[=]$

c. $[146 \mathrm{C}>\mathrm{G}] ;[=$

c. $[998 \mathrm{C}>\mathrm{T}] ;[=]$

c. [1229T > C]; [=]

c. $[1744 T>C] ;[=]$

c. $[1960 \mathrm{C}>\mathrm{A}] ;[=]^{\mathrm{b}}$

c. [2119T > C]; [=]

\section{Synonymous variants}

c. $[162 \mathrm{~T}>\mathrm{C}] ;[=]$

c. $[657 \mathrm{~T}>\mathrm{C}] ;[=]$

c. $[735 \mathrm{C}>\mathrm{T}] ;[=]$

c. $[4578 \mathrm{C}>\mathrm{T}] ;[=]$

c. $[5793 \mathrm{~T}>\mathrm{C}] ;[=]$

c. $[8592 \mathrm{C}>\mathrm{T}] ;[=]$

$\begin{array}{lll}\text { rs3218690 } & 05 & \text { (p.=) Tyr54 } \\ \text { rs2235003 } & 08 & \text { (p.=) Cys219 } \\ \text { rs3218674 } & 09 & \text { (p.=) Val245 } \\ \text { rs1800889 } & 32 & \text { (p.=) Pro1526 } \\ \text { rs3092910 } & 41 & \text { (p.=) Ala1931 } \\ \text { rs56025670 } & 61 & \text { (p.=) Tyr2864 }\end{array}$

Probably damaging

Probably damaging

Benign

Benign

Possibly damaging

Possibly damaging

Benign

Benign

Benign

Probably damaging

Possibly damaging

Probably damaging

Possibly damaging

Benign

Benign

Benign

Benign

Benign

Possibly damaging

Probably damaging

Non-synonymous variant subtotals

N/A

N/A

N/A

N/A

N/A

N/A

\section{Synonymous variant subtotals}

Variant totals for all

$\begin{array}{rrr}1 & 1 & 0 \\ 1 & 0 & 1 \\ 1 & 1 & 0 \\ 1 & 1 & 0 \\ 1 & 1 & 0 \\ 2 & 1 & 1 \\ 1 & 0 & 1 \\ 1 & 1 & 0 \\ 2 & 2 & 0 \\ 1 & 1 & 0 \\ 1 & 0 & 1 \\ 4 & 1 & 3 \\ 1 & 0 & 1 \\ 8 & 0 & 8 \\ 9 & 7 & 2 \\ 1 & 1 & 0 \\ 36 & 22 & 14 \\ 3 & 3 & 0 \\ 1 & 1 & 0 \\ 1 & 1 & 0 \\ \mathbf{7 7} & \mathbf{4 5} & \mathbf{3 2}\end{array}$

Nomenclature style is taken from the Human Genome Variation Society recommendations, found at http://www.hgvs.org/mutnomen/

a PolyPhen-2 v2.2.2, updated February 15, 2012. Available from: http://genetics.bwh.harvard.edu/pph2/index.shtm/

${ }^{b}$ While not in dbSNP, this variant was noted in Ref. (16).

'There is one Caucasian patient who had an indeterminate genotype in this codon. The patient is represented in each heterozygous category independently in this table. c.[5557G > A (;) 5558A > T] p.[(Asp1853?]];[?]]. Amino acid change possibilities: AAT, asparagine (polar, neutral, benign); ATT, isoleucine (non-polar, neutral, possibly damaging); GAT, no change on one allele; GTT, valine (non-polar, neutral, possibly damaging).

${ }^{d}$ This variant was not in any publications or in dbSNP prior to our submission.

determine the haplotype for any of the patients with multiple variants.

We performed an analysis for exonic copy number and found no variations in exonic copy number within this population.

\section{DISCUSSION}

As part of the original research design, the ATM gene was investigated as there was concern that the AI patient population was more sensitive to the effects of therapeutic radiation. Fear of this treatment related side-effect could potentially contribute to the commonly observed treatment delays observed in this patient population. A total of $101 \mathrm{AI}$ and 101 non-AI participated in the ATM study (17). This study provided new information on the ethnic distribution of ATM variants in a regional US population, and is the first to determine the prevalence of ATM variants in AI cancer patients. 
Table 2 | Prevalence (95\% confidence limits) of most common ATM variants.

\begin{tabular}{|c|c|c|c|c|}
\hline SNP & American Indians & Non-American Indians & $P$-value* & PolyPhen \\
\hline c. $5557 \mathrm{G}>\mathrm{A}$ & $14 \%(8 \%, 22 \%)$ & $25 \%(17 \%, 35 \%)^{a}$ & 0.07 & Probably benign \\
\hline c. $4578 C>T$ & $12 \%(6 \%, 20 \%)$ & $11 \%(6 \%, 19 \%)$ & 1.0 & $N A^{b}$ \\
\hline c. $4258 C>T$ & $2 \%(0.2 \%, 7 \%)$ & $7 \%(3 \%, 14 \%)$ & 0.17 & Benign \\
\hline c. $4138 \mathrm{C}>\mathrm{T}$ & $8 \%(4 \%, 15 \%)$ & $0 \%(0 \%, 4 \%)$ & 0.007 & Benign \\
\hline c. $3161 C>G$ & $3 \%(0.6 \%, 9 \%)$ & $1 \%(0.03 \%, 4 \%)$ & 0.61 & Probably damaging \\
\hline Any variant & $40 \%(30 \%, 50 \%)$ & $48 \%(38 \%, 58 \%)$ & 0.32 & - \\
\hline
\end{tabular}

*P-value for the null hypothesis of equal prevalence in American Indians and non-American Indians patients.

${ }^{a}$ Three homozygous cases.

${ }^{b}$ Synonymous change.

Table 3 | Summary of ATM variants.

Patients with multiple variant combinations

\begin{tabular}{|c|c|c|c|}
\hline \multicolumn{3}{|c|}{ Patients with multiple variant combinations } & $\begin{array}{l}\text { Number of } \\
\text { patients with } \\
\text { combination }\end{array}$ \\
\hline c. $998 \mathrm{C}>\mathrm{T}$ & c. $5557 \mathrm{G}>\mathrm{A}$ & & 1 \\
\hline c. $1229 \mathrm{~T}>\mathrm{C}$ & c. $5557 \mathrm{G}>\mathrm{A}$ & & 1 \\
\hline c. $4578 \mathrm{C}>\mathrm{T}$ & c. $5557 \mathrm{G}>\mathrm{A}$ & & 4 \\
\hline c. $378 \mathrm{~T}>\mathrm{A}$ & c. $657 \mathrm{~T}>\mathrm{C}$ & & 1 \\
\hline c. $2119 T>C$ & c. $2149 \mathrm{C}>\mathrm{T}$ & c. $4578 \mathrm{C}>\mathrm{T}$ & 1 \\
\hline c. $4258 \mathrm{C}>\mathrm{T}$ & c. $5071 \mathrm{~A}>\mathrm{C}$ & & 1 \\
\hline c. $4258 \mathrm{C}>\mathrm{T}$ & c. $4578 \mathrm{C}>\mathrm{T}$ & & 1 \\
\hline c. $735 \mathrm{C}>\mathrm{T}$ & c. $4258 \mathrm{C}>\mathrm{T}$ & & 1 \\
\hline c. $5557 \mathrm{G}>\mathrm{A}$ & c. $5558 \mathrm{~A}>\mathrm{T}$ & & 1 \\
\hline c. $2572 \mathrm{~T}>\mathrm{C}$ & c. $3161 C>G$ & & 1 \\
\hline c. $202 A>G$ & c. $3161 C>G$ & c. $5557 \mathrm{G}>\mathrm{A}$ & 1 \\
\hline c. $146 C>G$ & c. $5557 \mathrm{G}>\mathrm{A}$ & & 1 \\
\hline c. $4138 \mathrm{C}>\mathrm{T}$ & c. $4578 \mathrm{C}>\mathrm{T}$ & & 1 \\
\hline
\end{tabular}

Our results indicate that the variants found in the AI patient population, with the exception of the $4138 \mathrm{C}>\mathrm{T}$ variant, are also found in the non-AI population. In fact, there were more variants identified in the non-AI population. The most prevalent variant found in both populations was the $5557 \mathrm{G}>\mathrm{A}$ variant - resulting in the replacement of aspartic acid with asparagine, a substitution that the PolyPhen- 2 tool predicts to be benign. At the time of writing, there are at least 11 published studies of the possible link between this particular variant and normal tissue toxicity after radiation therapy. The outcomes of these studies are inconsistent, ranging from studies finding an increased risk of toxicity among carriers of the minor allele to a decreased risk, and with several studies finding no significant link. A large individual patient level meta-analysis of all the available data is being conducted by the international Radiogenomics Consortium (RGC), see below.

The c.5557G > A SNP has also been intensively studied with respect to possible association with breast cancer susceptibility. Recent meta-analyses found no evidence of such an association (18), although interestingly in the present context, in a sub-group analysis stratifying for ethnicity AIs did show an increased odds ratio of 2.19 (with 95\% CI 1.38-3.47). However, further studies are needed to confirm this finding.
A recent attempt at validating a large number of SNP's that have previously been reported by various groups to be associated with toxicity after radiation therapy showed that not a single one of these could be independently validated, in other words the published literature is dominated by false-positive associations (19). In an attempt to synthesize information from multiple studies and to push the number of cases in future studies into the range of 2,000-10,000 cases, an international RGC was formed in November 2009 (20). The RGC has more than 110 members mainly from Asia, Europe, and North America with expertise in radiation biology, radiation oncology, epidemiology, genetics, radiation physics, statistics, or bioinformatics. The data from the present study are also included in the RGC virtual databank. Relatively small studies like the present one are of great potential value as haplotypes will tend to differ between various ethnic groups. One could envision a research strategy where the predictive strength of various variants was established in the larger cohorts, potentially using genome wide association methodologies (discovery phase), validated in the same population whereafter the most promising among the validated variants would subsequently be tested in populations such as the AI. It is also possible that rare variants could be relatively more common in some populations due to founder mutations. However, in the present study there was no evidence of this, with the possible exception of the c.4138C > T SNP among the AI patients.

It was originally planned to correlate the variant data to patient toxicity data with the hopes of finding a predictive assay. However, the analysis was not performed because of the heterogeneity in disease sites, and the fact that the distribution among sites were different in the AI and non-AI groups. It is more realistic that discovery of variants linked with toxicity will come from much larger populations, and once strong candidate variants have been identified the prevalence of these among the AI patients can be established.

\section{CONCLUSION}

There is no support in our study for the hypothesis that a difference in prevalence or type of ATM variants explains the different spectrum of side-effects seen after radiotherapy in AI versus non-AI patients. Correlation to variant and toxicities was not performed as the study was underpowered. The successful completion of this study is indicative of the trust we have garnered with tribal entities throughout Western SD, and has positioned us to now become 
part of the worldwide RGC, where we will help to potentially solve the mystery of finding a predictor of increased radiosensitivity.

\section{ACKNOWLEDGMENTS}

This study was supported by a grant from the National Cancer Institute (5U56CA099010).

\section{REFERENCES}

1. Bentzen SM, Dörr W, Anscher MS, Denham JW, Hauer-Jensen M, Marks LB, et al. Normal tissue effects: reporting and analysis. Semin Radiat Oncol (2003) 13:189-202. doi:10.1016/S1053-4296(03)00036-5

2. Safwat A, Bentzen SM, Turesson I, Hendry JH. Deterministic rather than stochastic factors explain most of the variation in the expression of skin telangiectasia after radiotherapy. Int J Radiat Oncol Biol Phys (2002) 52:198-204. doi:10.1016/S0360-3016(01)02690-6

3. Turesson I, Nyman J, Holmberg E, Odén A. Prognostic factors for acute, and late skin reactions in radiotherapy patients. Int J Radiat Oncol Biol Phys (1996) 36:1065-75. doi:10.1016/S0360-3016(96)00426-9

4. Bentzen SM. Preventing or reducing late side effects of radiation therapy: radiobiology meets molecular pathology. Nat Rev Cancer (2006) 6:702-13. doi:10.1038/nrc1950

5. Savitsky K, Bar-Shira A, Gilad S, Rotman G, Ziv Y, Vanagaite L, et al. A single ataxia telangiectasia gene with a product similar to PI-3 kinase. Science (1995) 268:1749-53. doi:10.1126/science.7792600

6. Sedgwick R, Boder E. Ataxia-telangiectasia. In: Vianney De Jong JMB, editor. Hereditary Neuropathies and Spino-cerebellar Atrophies. Amsterdam: Elsevier (1991). p. 347-423.

7. Taylor A, Harnden D, Arlett C, Harcourt SA, Lehmann AR, Stevens S, et al. Ataxia telangiectasia: a human mutation with abnormal radiation sensitivity. Nature (1975) 258:427-9. doi:10.1038/258427a0

8. Swift M, Morrell D, Cromartie E, Chamberlin AR, Skolnick MH, Bishop DT. The incidence and gene frequency of ataxia-telangiectasia in the United States. Am J Hum Genet (1986) 39:573-83.

9. Swift M, Morrell D, Massey RB, Chase CL. Incidence of cancer in 161 families affected by ataxia-telangiectasia. N Engl J Med (1991) 325:1831-6. doi:10.1056/NEJM199112263252602

10. Petereit DG, Rogers D, Burhansstipanov L, Kaur J, Govern F, Howard SP, et al. Walking forward: the South Dakota native American project. J Cancer Educ (2005) 20:65-70. doi:10.1207/s15430154jce2001s_14

11. Petereit DG, Guadagnolo BA, Wong R, Coleman CN. Addressing cancer disparities among American Indians through innovative technologies and patient navigation: the walking forward experience. Front Oncol (2011) 1:11. doi:10. 3389/fonc. 2011.00011

12. Available from: http://chromium.liacs.nl/lovd/refseq/ATM_codingDNA.html

13. Sipahimalani P, Spinelli J, Lai A. A systematic evaluation of the ataxia telangiectasia mutated gene does not show an association with non-Hodgkin lymphoma. Int J Cancer (2007) 121:1967-75. doi:10.1002/ijc.22888

14. Available from: http://sourceforge.net/projects/staden/

15. Available from: http://www.hgvs.org/mutnomen/

16. Tavtigian SV, Oefner PJ, Babikyan D, Hartmann A, Healey S, Le CalvezKelm F, et al. Rare, evolutionarily unlikely missense substitutions in ATM confer increased risk of breast cancer. Am J Hum Genet (2009) 85(4):427-46. doi:10.1016/j.ajhg.2009.08.018

17. Petereit DG, Burhansstipanov L. Establishing trusting partnerships for successful recruitment of American Indians to clinical trials. Cancer Control (2008) 15:260-8.

18. Mao C, Chung VC, He BF, Luo RC, Tang JL. Association between ATM 5557G>A polymorphism and breast cancer risk: a meta-analysis. Mol Biol Rep (2012) 39:1113-8. doi:10.1007/s11033-011-0839-6

19. Barnett GC, Coles CE, Elliott RM, Baynes C, Luccarini C, Conroy D, et al. Independent validation of genes and polymorphisms reported to be associated with radiation toxicity: a prospective analysis study. Lancet Oncol (2012) 13:65-77. doi:10.1016/S1470-2045(11)70302-3

20. West C, Rosenstein B, Alsner J, Azria D, Barnett G, Begg A, et al. Establishment of a radiogenomics consortium. Int J Radiat Oncol Biol Phys (2010) 76:1295-6. doi:10.1016/j.ijrobp.2009.12.017

Conflict of Interest Statement: The authors declare that the research was conducted in the absence of any commercial or financial relationships that could be construed as a potential conflict of interest.

Received: 04 October 2013; accepted: 13 December 2013; published online: 30 December 2013.

Citation: Petereit DG, Hahn LJ, Kanekar S, Boylan A, Bentzen SM, Ritter $M$ and Moser AR (2013) Prevalence of ATM sequence variants in Northern plains American Indian cancer patients. Front. Oncol. 3:318. doi: 10.3389/fonc.2013.00318

This article was submitted to Radiation Oncology, a section of the journal Frontiers in Oncology.

Copyright (c) 2013 Petereit, Hahn, Kanekar, Boylan, Bentzen, Ritter and Moser. This is an open-access article distributed under the terms of the Creative Commons Attribution License (CC BY). The use, distribution or reproduction in other forums is permitted, provided the original author(s) or licensor are credited and that the original publication in this journal is cited, in accordance with accepted academic practice. No use, distribution or reproduction is permitted which does not comply with these terms. 